\title{
Long-term neuropathological and/or neurobehavioral effects of antenatal corticosteroid therapy in animal models: a systematic review
}

Cite this article as: Johannes L. van der Merwe, Adalina Sacco, Jaan Toelen and Jan Deprest, Longterm neuropathological and/or neurobehavioral effects of antenatal corticosteroid therapy in animal models: a systematic review, Pediatric Research doi:10.1038/s41390-019-0712-1

This Author Accepted Manuscript is a PDF file of an unedited peer-reviewed manuscript that has been accepted for publication but has not been copyedited or corrected. The official version of record that is published in the journal is kept up to date and so may therefore differ from this version.

Terms of use and reuse: academic research for non-commercial purposes, see here for full terms. https://www.nature.com/authors/policies/license.html\#AAMtermsV1 


\section{AUTHOR ACCEPTED MANUSCRIPT}

Long-term neuropathological and/or neurobehavioral effects of antenatal corticosteroid therapy in animal models: a systematic review

Johannes L. van der Merwe ${ }^{1,2}$, Adalina Sacco ${ }^{3}$, Jaan Toelen ${ }^{1,4}$, Jan Deprest ${ }^{1,2,3}$

${ }^{1}$ Department of Development and Regeneration, Cluster Woman and Child, Faculty of Medicine, KU Leuven, Leuven, Belgium.

2 Department of Obstetrics and Gynaecology, Fetal Medicine Unit, UZ Leuven, Leuven, Belgium.

${ }^{3}$ Institute for Women's Health, University College London, London, UK.

${ }^{4}$ Department of Pediatrics, Division Woman and Child, University Hos pitals Leuven, Leuven, Belgium

Correspondence: $\quad$ Dr Johannes van der Merwe

KU Leuven, Faculty of Medicine

Department of Development and Regeneration

UZ Herestraat 49 bus 805,3000 Leuven, Belgium

E-mail: hannes.vandermerwe@uzleuven.be

Author contribution: All authors have contributed to the writing of this paper. Jvdm and AS performed the search and extracted the data. JT and JD guided the results and merged and corrected the work.

Disclosure statement: All authors report no conflicts of interest.

Funding: JvdM is funded with support of the Erasmus + Programme of the European Union (Framework Agreement Number: 2013-0040). This publication reflects the views only of the 


\section{AUTHOR ACCEPTED MANUSCRIPT}

author, and the Commission cannot be held responsible for any use which may be made of the information contained therein.

Systematic Review 


\section{AUTHOR ACCEPTED MANUSCRIPT}

\section{Abstract:}

\section{Background}

Antenatal corticosteroids (ACS) are recommended to all women at risk for preterm delivery, currently there is controversy about the subsequent long-term neurocognitive sequelae. This systemic review summarizes the long-term neurodevelopmental outcomes after ACS therapy in animal models.

\section{Methods}

An electronic search strategy incorporating MeSH and keywords was performed using all known literature databases and in accordance with PRISMA guidance. (PROSPERO CRD42019119663).

\section{Results}

Of the 669 studies identified eventually 64 were included. The majority of studies utilized dexamethasone at relative high dosages and primarily involved rodents. There was a high risk of bias, mostly due to lack of randomization, allocation concealment and blinding. The main outcomes reported on was neuropathological, particularly glucocorticoid receptor expression and neuron densities, and neurobehavior. Overall there was an upregulation of glucocorticoid receptors with lower neuron densities and a dysregulation of the dopaminergic and serotonergic systems. This coincided with various adverse neurobehavioral outcomes.

\section{Conclusions}

In animal models ACS consistently lead to deleterious long-term neurocognitive effects. This may be due to the specific agents, i.e. dexamethasone, or the repetitive/higher total dosing used. ACS administration varied significantly between studies and there was a high risk of bias. Future research should be standardized in well characterized models. 
(C) 2019 Macmillan Publishers Limited, part of Springer Nature. 


\section{AUTHOR ACCEPTED MANUSCRIPT}

\section{Background}

Glucocorticoids (GCs) are essential in the biological processes required for the transition from intrauterine to extrauterine life. The overall action of endogenous GCs is to trigger organ maturation, thereby enabling the lungs, liver, gastrointestinal tract, thyroid, adrenals and kidneys to function and sustain life outside the uterine environment (1). GCs are also crucial for normal brain maturation, as they initiate terminal maturation, remodel axons and dendrites and affect cell survival (2). Both suppressed and elevated GC levels can impair brain development and functioning (3).

Since 1994, antenatal corticosteroids (ACS) have been recommended to all women at risk for delivery between 24 and 34 weeks of gestation (4). As ACS are effective not only in reducing perinatal morbidity, i.e. respiratory distress syndrome, intraventricular hemorrhage, necrotizing enterocolitis and sepsis but also the mortality that is associated with prematurity (5). Although the beneficial short-term outcomes of ACS therapy were evident from an early stage, longer-term outcomes, including neurodevelopment, have been less extensively studied. A systematic review of maternal ACS administration in pregnancy reported improved neurodevelopmental outcomes in these children. However, this systematic review consisted mostly of nonrandomized studies and reported on crude neurodevelopmental outcomes (6). Therefore, although ACS therapy appears safe and effective, current clinical data cannot define the precise effect of ACS therapy on future neurodevelopment. Long-term effects of ACS therapy have recently been described in a longitudinal study suggesting that ACS therapy yields persistent changes in HPA-axis reactivity into late adolescence and may confer increased vulnerability for developing stress-related disorders (7). 
In view of the unclear long-term outcomes in clinical studies and the widespread use of ACS, it is reasonable to reflect on animal studies to guide future research. Despite a number of preclinical studies investigating the neurocognitive effect of ACS, the majority have reported only on direct or short-term effects $(8,9)$. Additionally, the effects being investigated are not standardized or consistent between studies. To date there has been no systemic review summarizing the long-term neurodevelopmental outcomes after ACS therapy in preclinical models. 


\section{AUTHOR ACCEPTED MANUSCRIPT}

\section{Methods}

\section{Protocol and Registration}

This systematic review was performed in accordance with the Preferred Reporting Items for Systematic reviews and Meta-analyses (PRISMA) guidance (10). The protocol was registered with the International Prospective Register of Systematic Reviews (PROSPERO) (CRD42019119663)

\section{Literature search strategy}

A literature search was conducted in PubMed, MEDLINE, EMBASE, Scopus, Web of Science and the Cochrane Library. The electronic search strategy included both Medical Subject Headings (MeSH) and keywords (Supplement 1). Reference lists and topic-related reviews were checked manually to identify further relevant papers. Zotero 5.0 (George Mason University, Virginia, US) was used to coordinate study screening and data collection.

\section{Inclusion and exclusion criteria}

All randomized, cohort, case-controlled studies and case series reporting on the use of ACS in animals were considered eligible. No date or language restrictions were applied. Systematic reviews, narrative review articles and editorials were excluded. Studies were excluded if corticosteroids were administered postnatally and if no long-term or neurological outcomes were reported in the offspring. For the purposes of this study, a post-natal age of seven days or more was considered as long term. Neurological outcomes were defined as any neuropathological, neurobehavioral or neuroimaging (i.e. CT and MRI) results. 


\section{AUTHOR ACCEPTED MANUSCRIPT}

Study selection

JvdM and AS independently screened titles and abstracts and thereafter performed a full text review of all studies. Disagreements were resolved by consensus. A low threshold for full-text retrieval and review was used.

\section{Data extraction}

JvdM and AS independently extracted data and entered this into a standardized Excel (Microsoft Corp, Seattle, Washington, US) form (Supplement 2). Disagreements were resolved by consensus. Information noted included study design, animal species, number of animals and gestation for that model. Treatment data recorded included type of corticosteroid, route of administration, number of doses and gestational age of treatment. Treatment regimens were grouped into those administering a "single course" of corticosteroids i.e. a single or two doses given within 48 hours of each other and those administering "multiple courses" of corticosteroids i.e. repeated doses given over more than two days. The dose of corticosteroids given was noted and converted into $\mathrm{mg} / \mathrm{kg}$ based on information provided in the study, if not already given as such. This was then multiplied by the number of doses given in order to give a total administered dose in $\mathrm{mg} / \mathrm{kg}$. We calculated the average human total dose of antenatal corticosteroids to be $0.4 \mathrm{mg} / \mathrm{kg}(12 \mathrm{mg}$ betamethasone or dexamethasone given twice, with an average female weight of $60-80 \mathrm{~kg}$ ). We therefore empirically grouped the total study dosing regimens into one of the following: $<0.2 \mathrm{mg} / \mathrm{kg}, \quad 0.2-0.4 \mathrm{mg} / \mathrm{kg}$ (clinical equivalent dosing), $0.41-1.0 \mathrm{mg} / \mathrm{kg}$, and $>1.0 \mathrm{mg} / \mathrm{kg}$. Outcome data recorded included age of animals at assessment, neuropathology 


\section{AUTHOR ACCEPTED MANUSCRIPT}

parameters, neurobehavioral and neuroimaging outcomes, as well as the overall effect of ACS in that study.

Risk of bias

Risk of bias was independently assessed by JvdM and AS using the Systematic Review Centre for Laboratory Animal Experimentation's (SYRCLE's) tool for animal interventional studies (11). Study quality was noted on a standardized Excel form. Disagreements were resolved by consensus.

Data synthesis and statistical methods

Meta-analysis and comparative statistics were not planned as it was anticipated that the data would be difficult to collate or compare. Therefore, heterogeneity between studies was not calculated and narrative results and descriptive statistics were produced. 


\section{AUTHOR ACCEPTED MANUSCRIPT}

\section{Results}

\section{Study selection}

The electronic search identified 575 studies published until October 2018 (Figure 1); handsearching of reference lists identified a further 94 studies. Following removal of duplicate studies (273), 396 studies were screened by title and abstract and a further 286 were excluded as irrelevant. Full text review of the remaining 110 studies was conducted, and 46 were excluded. The main reasons for study exclusion at any stage were: no antenatal corticosteroids given $(56.6 \%, 188 / 332)$, no long-term outcomes $(16.0 \%, 53 / 332)$, reviews and editorials $(14.8 \%, 49 / 332)$ and no neuropathological, neurobehavioral or neuroimaging outcomes (9.6\%, 32/332). After exclusions, 64 studies were included for systematic review.

\section{Study characteristics}

Characteristics of included studies are shown in Table 1 . The majority of studies were in the rat $(70.3 \%, 45 / 64)$; other animal models included the mouse $(14.1 \%, 9 / 64)$, non-human primates $(6.25 \%, 4 / 64)$ the sheep $(4.7 \%, 3 / 64)$, and the guinea pig $(4.7 \%, 3 / 64)$. Most studies $(93.8 \%, 60 / 64)$ compared corticosteroids to a non-active control (e.g. saline), although four studies (6.3\%) compared corticosteroids to no treatment. All included studies evaluated animals born at term gestations.

\section{Risk of bias}

Risk of bias of included studies is shown in Figure 2. Most studies had a high risk of bias due to the lack of random sequence generation $(65.7 \%, 42 / 64)$, allocation concealment 


\section{AUTHOR ACCEPTED MANUSCRIPT}

performed $(75 \%, 48 / 64)$ and blinding of caregivers $(10.9 \%, 7 / 64)$ or assessors $(29.7 \%$, 19/64).

\section{ACS treatment}

Details of ACS treatment is shown in Table 2. Overall, dexamethasone was the most commonly studied corticosteroid $(81.3 \%, 52 / 64)$; betamethasone was used in $17.2 \%$ of studies (11/64) and both corticosteroids were used in one mouse study. Two thirds of studies administered multiple courses of corticosteroids $(67.2 \%, 43 / 64)$ with the total administered dose varying from $0.1 \mathrm{mg} / \mathrm{kg}$ to $70 \mathrm{mg} / \mathrm{kg}$. Eighteen studies $(28.1 \%)$ administered a total dose of corticosteroids which was equivalent to that used in humans $(0.2-0.4 \mathrm{mg} / \mathrm{kg})$ while the majority of studies $(76.6 \%, 49 / 64)$ administered a total dose higher than $0.4 \mathrm{mg} / \mathrm{kg}$. In two studies $(3.1 \%, 2 / 64)$ the effects of a brief low dosage ACS exposure was also explored.

\section{Growth - body weight}

There was no routine reporting on the general health of the animals at time of assessment or harvesting. Though, $50.0 \%(32 / 64)$ of the studies did report on the body weight at the time of the last assessment. Only one study reported an increased weight at time of harvesting, a study of NHP using a multiple day high DM dose (32). While 16 reported a decrease in bodyweight in those exposed to ACS, herein DM was used in 13/16 $(14,17,19,23,27,29,30,39,42,50,57,73,75)$ and $B M$ only in $3 / 16(26,31,56)$. Furthermore, only $10.9 \%(7 / 64)$ reported on the brain weight or volume at time of harvesting wherein $57.1 \%$ (4/7) reported a decrease of brain weight after the exposure of ACS $(19,56,59,72)$. 


\section{AUTHOR ACCEPTED MANUSCRIPT}

Outcomes assessment

Neuropathology was the commonest outcome reported, either alone $(28.1 \%, 18 / 64)$ or in combination with neurobehavioral assessment $(42.2 \%, 27 / 64)$ or neuroimaging $(3.1 \%$, $2 / 64$ ). Neurobehavioral assessment alone was assessed in $25.0 \%$ of studies (16/64), and one study (1.6\%) assessed all three outcomes (Figure 3 ). The average age at final assessment was 157 days (range 10 - 1800 days)

Neuropathological assessments performed

In the 48 studies that reported on a neuropathological outcomes, dexamethasone was most commonly used (79.2\%, 38/48). Additionally, in a third $(35.4 \%, 17 / 48)$ of the neuropathological outcome studies, ACS was used at a clinical equivalent dose while the majority of studies $(60.4 \%, 29 / 48)$ used an accumulative dose higher than $0,4 \mathrm{mg} / \mathrm{kg}$. The commonest neuropathological outcomes reported was glucocorticoid receptor (GR) quantification $(29.2 \%, 14 / 48)$, neuron density $(16.7 \%, 8 / 48)$ or a form of dendritic assessment $(16.7 \%, 8 / 48)$. The complete breakdown of reported neuropathological outcomes are displayed in Table 3.

Neurobehavioral assessments performed

Neurobehavioral assessments were reported in 44 studies in only three of the species. As noted above, most studies reported on the effects of DM and used almost exclusively rat and mice species. Neurobehavioral outcomes assessed are summarized in Table 4.

Neuroimaging assessments performed 


\section{AUTHOR ACCEPTED MANUSCRIPT}

In one study CT imaging was used to quantify total brain volumes in rats (64). Herein, antenatal DM did not lead to any difference in brain volumes at 3 months of ages. A further two studies utilized MRI to quantify the hippocampal volumes and T2-signal intensities in the rat (62) and NHP (13). In both of these studies antenatal DM at a dose of 0,80mg/kg and $10 \mathrm{mg} / \mathrm{kg}$ respectively, resulted in lower hippocampal volumes. 


\section{AUTHOR ACCEPTED MANUSCRIPT}

\section{Discussion}

To date there has been no systemic review summarizing the long-term neurodevelopmental outcomes after ACS therapy in preclinical models. From this review, intrauterine exposure to synthetic GCs lead consistently to deleterious long-term neurocognitive effects. These outcomes may be due to the specific agents, i.e. dexamethasone, or the repetitive or higher total dosing used. ACS administration varied significantly between studies and most studies suffered from a high risk of bias. Neuropathological outcomes were most commonly reported, specifically the expression of GR, while reduced neurobehavioral functioning was reported in mainly rodent species.

Synthetic GCs are agonists of the GR and predominantly act via genomic effects mediated by the GR, a nuclear transcription factor. Because of its marked GR expression, the fetal lung is one of the primary targets of synthetic GCs administered to expedite fetal development. The effects of ACS on the fetal and neonatal lung have been reviewed elsewhere (5), but their impact on other organ systems with high GR expression including the brain and kidney have mostly been assessed in short-term outcomes (9). In this review, the commonest longterm neuropathological outcome reported on was the expression of GR in mostly the hippocampus and hypothalamus. Herein, both with BM and DM, in small and large animal models mainly induced an upregulation of GRs $(20,21,30,41,49,73)$ although four of these studies used multiple DM dosing. However, in two studies a down regulation of GR was noted although in these an oral multiple day DM dosing was used $(17,43)$. The ultimate effect of this dysregulation on the GR can have a significant inhibitory downstream effect on the developing fetal brain and HPA axis, leading to profound programming influences on 


\section{AUTHOR ACCEPTED MANUSCRIPT}

the nervous system and henceforth an increase the risk for emotional and cognitive impairments (76). The possible mechanisms involved are depicted in Figure 4.

GCs are critical for normal brain development, exerting direct effects on neuronal growth, cell to cell interactions and neuronal reorganization (79). The mechanisms regulating the maturational effects of GCs on various fetal organs are complex. However, exposure of the developing brain to inappropriate levels of GCs at critical developmental time windows can modify both the structure and function of neuronal cells. The majority of studies used multiple or repetitive doses over multiple days, consequently in most studies there were a high total dose exposure of $0.4 \mathrm{mg} / \mathrm{kg}$ or more. Previously in small animal studies, ACS was associated with delayed growth of the whole body and brain, as well as altered behavior studies at birth $(80,81)$. From this review, there was an inconsistent long-term impact on brain and/or body weight and size. In those studies that used a total dose of $\leq 0.4 \mathrm{mg} / \mathrm{kg}$, ACS exposure was not associated with a reduction of long-term body or brain weight $(15,24,25,40,58,68)$. However, in one study a single course of $\mathrm{BM}$ exposure lead to a significant reduction in both body and brain weights (56). In sheep, fetal exposure to repeated doses of maternal betamethasone results in significant reductions in fetal brain weight that persist until 3 years of age (82).

Gross changes in brain growth are the result of specific alterations in neuronal development and cell death. It has previously been noted that the cellular proliferation in the brain of neonatal rats is acutely decreased by betamethasone treatments and reductions in brain weight persist until at least 3 weeks of postnatal age (25). As with prenatal stress exposure, ACS can also influence fetal brain development by changing neuronal migration, synaptic 


\section{AUTHOR ACCEPTED MANUSCRIPT}

plasticity, and neurotransmitter activity (83). In this review some studies observed altered neuronal states that lead to persistent lower neuron densities especially in the hippocampus $(13,73)$ with ongoing amplified apoptosis (67) and decreased proliferation $(28,33,40,58)$ being reported. Furthermore, the protective negative feedback loop of the HPA axis is mediated by cortisol binding to receptors in especially the hypothalamus, hippocampus and prefrontal cortex. It was foreseeable that most studies in this review noted alterations in these specific regions.

Inhibiting or turning off the HPA response axis can lead to a direct effect on the dopaminergic and serotonergic systems. Studies noted that ACS exposure was associated with less dopaminergic cells in multiple brain regions including the amygdala and hypothalamus $(15,33,47,53,55,66)$ that also has an effect on the central norepinephrine and peripheral activation of the sympathetic nervous system (84). The meso-cortico-limbic system, mediated by dopamine release especially from the nucleus accumbens and ventral tegmental area, encodes the rewarding and reinforcing properties of natural reward behavior (85). Evidently any dysfunction of this system could lead to multiple neuropsychiatric conditions.

Moreover, the reprogramming of the HPA axis by ACS is also associated with lower neuron expression in the serotonergic system especially in the hypothalamus, hippocampus and frontal cortex $(15,51,55)$. The serotoninergic system, a neurotransmitter system implicated in stress regulation and etiology of affective disorders is therefore another target for ACS exposure (66). This review confirms the alterations in serotonin receptors (5-HT1A and 5HT2A) and transporters secondary to hippocampal and hypothalamus GR programming. 


\section{AUTHOR ACCEPTED MANUSCRIPT}

Additionally, ACS can also lead to altered glial astrocyte function. Astrocytes assume multiple roles in maintaining an optimally suited milieu for neuronal function from the production of trophic factors, regulation of neurotransmitters and ion concentrations, to the removal of toxins and debris from the cerebrospinal fluid (CSF) (86). Impairments in these and other functions, as well as physiological reactions of astrocytes to injury, can trigger or exacerbate neuronal dysfunction. In this review multiple studies noted the longterm dysregulation of neuroglia especially astrocytes $(67,70,74)$.

So far, it is clear that the developing brain, with the meso-cortico-limbic system as a focus point, is particularly sensitive to exogenous GCs. The hippocampus, which plays a central role in this system, has a myriad of complex functions within the brain. These include cognition, behavior, memory, coordination of the autonomic activity, and regulation of a number of endocrine systems $(87,88)$. Given this wide spectrum of regulatory roles it is apparent that it will have a profound impact in postnatal and adult life. In rats, prenatal DM exposure, resulted in more anxiety like behavior $(15,39,59)$, sex-specific alterations in motor activity and sexual behavior $(14,66)$, and impaired spatial memory $(19,29)$. While in mice, maternal administration ACS resulted in delayed development and impaired motoric function in the offspring (16) Even a single course of ACS resulted in affecting anxiety, memory and socialization behaviors $(72,74)$. In NHP, there was reduced sociability and increased motivation reward behavior (37) with dramatic differences in the hippocampal structure and developmental as quantified by MRI (13).

These results indicate that both DM and BM interfere with the developing brain but it remains unclear from clinical trials whether one corticosteroid (or one particular regimen) 


\section{AUTHOR ACCEPTED MANUSCRIPT}

has advantages over another (89). Both cross the placenta in their active form, and both have similar biologic activity with neither acting as a mineralocorticoid and both having weak immunosuppressive short-term effects (16). BM and DM differ only in the configuration of a single methyl group with subsequent different pharmacokinetics; BM has a larger volume of distribution and decreased clearance and thus a longer half-life. (90) In addition, the commonly available DM preparation contains a sodium metabisulfite preservative, and sulfite is neurotoxic. However, prenatal exposure to sulfite is likely to be low (because it is administered to the mother and may not reach the fetus at the same dose) (91). From this review both BM and DM resulted in long-term sequelae, with no clear benefit of one over another. As previously stated, most investigations used DM and mostly multiple dosing or courses, but even low dose or single courses of BM $(25,26,56,59,63,68)$ and $\operatorname{DM}(33,40,58,72)$ resulted in clear neuropathological and neurobehavioral deficits.

This systematic review and the assimilated research have limitations mostly due to the administration regimes chosen, the lack of stringent methodological approach and nonstandardized reporting. The dosing regimens are not clearly "clinical equivalent" using mostly multiple dosages over multiple days. The true fetal exposure is not quantified and therefore the differences that each species metabolism bring is not addressed. Most of the studies investigate DM while BM is more in clinical use. Also, the high bias risk due the lack of randomization, allocational and treatment concealment, and selective/incomplete outcome reporting limit the interpretation of these results. As with all translational research there is inherent risk that the risk or benefit can be overestimated due to publication bias. 


\section{AUTHOR ACCEPTED MANUSCRIPT}

Ultimately, there is always the problem of species-specific factors that influence the translational value of the relevant research.

To grasp the effect of ACS on the neuroendocrine maturation, the timing of maturation of the HPA axis relative to birth needs to be clearly comprehended. In animals that give birth to mature young (sheep, guinea pigs, and primates) maximal brain growth and a large proportion of neuroendocrine maturation (including corticosteroid receptor development) takes place in utero $(92,93)$. In contrast, in species that give birth to immature young (rats, rabbits, and mice), much neuroendocrine development occurs in the postnatal period (94). Therefore, maternal GC treatment in late gestation will impact on different stages of brain and HPA development depending on the species studied. Another important consideration when extrapolating among different studies and species is that of receptor sensitivity. Mice and rats are corticosensitive (high receptor affinity for GCs) compared with other species, such as guinea pigs and primates, which are considered corticoresistant (95).

\section{Conclusion}

In conclusion, many animal models have been used to highlight the efficacy and potential adverse effects of ACS. In this review, a general pattern is observed of consistent neurocognitive sequelae that ultimately lead to modulated fetal programming, the so-called Developmental Origins of Health and Disease hypothesis. The mechanistic view of an intrauterine factor mediating brain growth and neurocognitive development at a vulnerable time in gestation while subsequently resulting in permanent alterations is one that has been included in many neurocognitive and psychiatric conditions. Current research pertaining to 


\section{AUTHOR ACCEPTED MANUSCRIPT}

the neurocognitive effects of ACS consisted mostly of DM using repetitive and high dosages in rodent species. There is a new focus on ACS since the role and indication for ACS has recently rapidly expanded to include rescue and repeated dosages, and late pre-term birth. (96-98)

Preclinical research could help in defining the efficacy and long-term outcomes in future ACS research, but models needs to be standardized to help address the barriers in translational neuroscience research. Principles that could be followed are:

1. Adequate and appropriate dosages that could include dose-response curves

2. Define the time and gestational age window of exposure in a well-characterized model

3. Blinded, physiologically controlled reproducible studies

4. Histological and functional outcomes assessed acutely and long-term Furthermore imaging, especially $\mathrm{MRI}$, could help characterize the insults even better especially in a longitudinal models where the long-term impact needs to be defined. So far this has been underutilized in this area. 


\section{AUTHOR ACCEPTED MANUSCRIPT}

\section{References}

1. Fowden AL, Li J, Forhead AJ. Glucocorticoids and the preparation for life after birth: are there long-term consequences of the life insurance? Proc Nutr Soc 1998;57:113-22.

2. Meyer JS. Early adrenalectomy stimulates subsequent growth and development of the rat brain. Exp Neurol 1983;82:432-46.

3. Bohn MC. Glucocorticoid induced teratologies of the nervous system. Neurobehav Teratol Ed J Yanai Elsevier Biomed Press 1984;365-87.

4. Effect of corticosteroids for fetal maturation on perinatal outcomes. NIH Consensus Development Panel on the Effect of Corticosteroids for Fetal Maturation on Perinatal Outcomes. JAMA 1995;273:413-8.

5. Roberts D, Brown J, Medley N, Dalziel SR. Antenatal corticosteroids for accelerating fetal lung maturation for women at risk of preterm birth. Cochrane Database Syst Rev 2017;3:CD004454.

6. Sotiriadis A, Tsiami A, Papatheodorou S, Baschat AA, Sarafidis K, Makrydimas G. Neurodevelopmental Outcome After a Single Course of Antenatal Steroids in Children Born Preterm: A Systematic Review and Meta-analysis. Obstet Gynecol 2015;125:1385.

7. Ilg L, Kirschbaum C, Li S-C, Rosenlöcher F, Miller R, Alexander N. Persistent Effects of Antenatal Synthetic Glucocorticoids on Endocrine Stress Reactivity from Childhood to Adolescence. J Clin Endocrinol Metab [Internet] [cited 2018 Dec 17];Available from: https://academic.oup.com/jcem/advance-article/doi/10.1210/jc.2018-01566/5114456

8. Aghajafari F, Murphy K, Matthews S, Ohlsson A, Amankwah K, Hannah M. Repeated doses of antenatal corticosteroids in animals: A systematic review. Am J Obstet Gynecol 2002;186:843-9. 
9. Jobe AH. Animal Models of Antenatal Corticosteroids: Clinical Implications. Clin Obstet Gynecol 2003;46:174.

10. Moher D, Liberati A, Tetzlaff J, Altman DG. Preferred reporting items for systematic reviews and meta-analyses: The PRISMA statement. Int J Surg 2010;8:336-41.

11. Hooijmans CR, Rovers MM, de Vries RBM, Leenaars M, Ritskes-Hoitinga M, Langendam MW. SYRCLE's risk of bias tool for animal studies. BMC Med Res Methodol 2014;14:43.

12. Smith DJ, Joffe JM, Heseltine GF. Modification of prenatal stress effects in rats by adrenalectomy, dexamethasone and chlorpromazine. Physiol Behav 1975;15:461-9.

13. Uno $\mathrm{H}$, Eisele $\mathrm{S}$, Sakai $\mathrm{A}$, et al. Neurotoxicity of glucocorticoids in the primate brain. Horm Behav 1994;28:336-48.

14. Holson RR, Gough B, Sullivan P, Badger T, Sheehan DM. Prenatal dexamethasone or stress but not $\mathrm{ACTH}$ or corticosterone alter sexual behavior in male rats. Neurotoxicol Teratol 1995;17:393-401.

15. Muneoka K, Mikuni M, Ogawa T, et al. Prenatal dexamethasone exposure alters brain monoamine metabolism and adrenocortical response in rat offspring. Am J PhysiolRegul Integr Comp Physiol 1997;273:R1669-75.

16. Rayburn WF, Christensen HD, Gonzalez CL. A placebo-controlled comparison between betamethasone and dexamethasone for fetal maturation: Differences in neurobehavioral development of mice offspring. Am J Obstet Gynecol 1997;176:84251.

17. Brabham T, Phelka A, Zimmer C, Nash A, López JF, Vázquez DM. Effects of prenatal dexamethasone on spatial learning and response to stress is influenced by maternal factors. Am J Physiol-Regul Integr Comp Physiol 2000;279:R1899-909. 


\section{AUTHOR ACCEPTED MANUSCRIPT}

18. Christensen HD, Gonzalez CL, Stewart JD, Rayburn WF. Multiple courses of antenatal betamethasone and cognitive development of mice offspring. J Matern Fetal Med 2001;10:269-76.

19. Welberg LA, Seckl JR, Holmes MC. Prenatal glucocorticoid programming of brain corticosteroid receptors and corticotrophin-releasing hormone: possible implications for behaviour. Neuroscience 2001;104:71-9.

20. Dodic M, Peers A, Moritz K, Hantzis V, Wintour EM. No evidence for HPA reset in adult sheep with high blood pressure due to short prenatal exposure to dexamethasone. Am J Physiol Regul Integr Comp Physiol 2002;282:R343-350.

21. Banjanin S, Kapoor A, Matthews SG. Prenatal glucocorticoid exposure alters hypothalamic-pituitary-adrenal function and blood pressure in mature male guinea pigs. J Physiol 2004;558:305-18.

22. Burlet G, Fernette B, Blanchard S, et al. Antenatal glucocorticoids blunt the functioning of the hypothalamic-pituitary-adrenal axis of neonates and disturb some behaviors in juveniles. Neuroscience 2005;133:221-30.

23. Hougaard KS, Andersen MB, Kjaer SL, Hansen AM, Werge T, Lund SP. Prenatal stress may increase vulnerability to life events: comparison with the effects of prenatal dexamethasone. Brain Res Dev Brain Res 2005;159:55-63.

24. McArthur S, McHale E, Dalley JW, Buckingham JC, Gillies GE. Altered Mesencephalic Dopaminergic Populations in Adulthood as a Consequence of Brief Perinatal Glucocorticoid Exposure. J Neuroendocrinol 2005;17:475-82.

25. Bruschettini M, van den Hove DLA, Gazzolo D, Steinbusch HWM, Blanco CE. Lowering the dose of antenatal steroids: the effects of a single course of betamethasone on 


\section{AUTHOR ACCEPTED MANUSCRIPT}

somatic growth and brain cell proliferation in the rat. Am J Obstet Gynecol 2006;194:1341-6.

26. Bruschettini M, van den Hove DLA, Timmers S, et al. Cognition- and anxiety-related behavior, synaptophysin and MAP2 immunoreactivity in the adult rat treated with a single course of antenatal betamethasone. Pediatr Res 2006;60:50-4.

27. Hauser J, Feldon J, Pryce CR. Prenatal dexamethasone exposure, postnatal development, and adulthood prepulse inhibition and latent inhibition in Wistar rats. Behav Brain Res 2006;175:51-61.

28. Korzhevskii DE, Gilerovich EG, Khozhai LI, Grigor'ev IP, Otellin VA. Modification of histogenetic processes in rat nervous tissue after administration of dexamethasone during prenatal development. Neurosci Behav Physiol 2006;36:537-9.

29. Oliveira M, Bessa JM, Mesquita A, et al. Induction of a hyperanxious state by antenatal dexamethasone: a case for less detrimental natural corticosteroids. Biol Psychiatry 2006;59:844-52.

30. Shoener JA, Baig R, Page KC. Prenatal exposure to dexamethasone alters hippocampal drive on hypothalamic-pituitary-adrenal axis activity in adult male rats. Am J Physiol Regul Integr Comp Physiol 2006;290:R1366-1373.

31. Velísek L. Prenatal exposure to betamethasone decreases anxiety in developing rats: hippocampal neuropeptide y as a target molecule. Neuropsychopharmacol Off Publ Am Coll Neuropsychopharmacol 2006;31:2140-9.

32. Hauser J, Dettling-Artho A, Pilloud S, et al. Effects of prenatal dexamethasone treatment on postnatal physical, endocrine, and social development in the common marmoset monkey. Endocrinology 2007;148:1813-22. 


\section{AUTHOR ACCEPTED MANUSCRIPT}

33. Leão P, Sousa JC, Oliveira M, Silva R, Almeida OFX, Sousa N. Programming effects of antenatal dexamethasone in the developing mesolimbic pathways. Synapse $2007 ; 61: 40-9$.

34. McArthur S, McHale E, Gillies GE. The size and distribution of midbrain dopaminergic populations are permanently altered by perinatal glucocorticoid exposure in a sexregion- and time-specific manner. Neuropsychopharmacol Off Publ Am Coll Neuropsychopharmacol 2007;32:1462-76.

35. Owen D, Matthews SG. Prenatal glucocorticoid exposure alters hypothalamic-pituitaryadrenal function in juvenile guinea pigs. J Neuroendocrinol 2007;19:172-80.

36. Setiawan E, Jackson MF, MacDonald JF, Matthews SG. Effects of repeated prenatal glucocorticoid exposure on long-term potentiation in the juvenile guinea-pig hippocampus. J Physiol 2007;581:1033-42.

37. Hauser J, Knapman A, Zürcher NR, et al. Effects of prenatal dexamethasone treatment on physical growth, pituitary-adrenal hormones, and performance of motor, motivational, and cognitive tasks in juvenile and adolescent common marmoset monkeys. Endocrinology 2008;149:6343-55.

38. Hossain A, Hajman K, Charitidi K, et al. Prenatal dexamethasone impairs behavior and the activation of the BDNF exon IV promoter in the paraventricular nucleus in adult offspring. Endocrinology 2008;149:6356-65.

39. Nagano M, Ozawa H, Suzuki H. Prenatal dexamethasone exposure affects anxiety-like behaviour and neuroendocrine systems in an age-dependent manner. Neurosci Res 2008;60:364-71. 


\section{AUTHOR ACCEPTED MANUSCRIPT}

40. Noorlander CW, Visser GHA, Ramakers GMJ, Nikkels PGJ, Graan PNE de. Prenatal corticosteroid exposure affects hippocampal plasticity and reduces lifespan. Dev Neurobiol 2008;68:237-46.

41. Sloboda DM, Moss TJM, Li S, Matthews SG, Challis JRG, Newnham JP. Expression of glucocorticoid receptor, mineralocorticoid receptor, and 11beta-hydroxysteroid dehydrogenase 1 and 2 in the fetal and postnatal ovine hippocampus: ontogeny and effects of prenatal glucocorticoid exposure. J Endocrinol 2008;197:213-20.

42. Hauser J, Feldon J, Pryce CR. Direct and dam-mediated effects of prenatal dexamethasone on emotionality, cognition and HPA axis in adult Wistar rats. Horm Behav 2009;56:364-75.

43. Diaz Heijtz R, Fuchs E, Feldon J, Pryce CR, Forssberg H. Effects of antenatal dexamethasone treatment on glucocorticoid receptor and calcyon gene expression in the prefrontal cortex of neonatal and adult common marmoset monkeys. Behav Brain Funct BBF 2010;6:18.

44. Kleinhaus K, Steinfeld S, Balaban J, et al. Effects of excessive glucocorticoid receptor stimulation during early gestation on psychomotor and social behavior in the rat. Dev Psychobiol 2010;52:121-32.

45. Neigh GN, Owens MJ, Taylor WR, Nemeroff CB. Changes in the vascular area fraction of the hippocampus and amygdala are induced by prenatal dexamethasone and/or adult stress. J Cereb Blood Flow Metab Off J Int Soc Cereb Blood Flow Metab 2010;30:1100-4.

46. Kjaer SL, Hougaard KS, Tasker RA, et al. Influence of diurnal phase on startle response in adult rats exposed to dexamethasone in utero. Physiol Behav 2011;102:444-52. 


\section{AUTHOR ACCEPTED MANUSCRIPT}

47. Oliveira M, Leão P, Rodrigues A-J, Pêgo J-M, Cerqueira J-J, Sousa N. Programming effects of antenatal corticosteroids exposure in male sexual behavior. J Sex Med $2011 ; 8: 1965-74$.

48. Roque S, Oliveira TG, Nobrega C, et al. Interplay between Depressive-Like Behavior and the Immune System in an Animal Model of Prenatal Dexamethasone Administration. Front Behav Neurosci 2011;5:4.

49. Li S, Nitsos I, Polglase GR, et al. The effects of dexamethasone treatment in early gestation on hypothalamic-pituitary-adrenal responses and gene expression at 7 months of postnatal age in sheep. Reprod Sci Thousand Oaks Calif 2012;19:260-70.

50. Liu W, Xu Y, Lu J, Zhang Y, Sheng H, Ni X. Swimming exercise ameliorates depressionlike behaviors induced by prenatal exposure to glucocorticoids in rats. Neurosci Lett 2012;524:119-23.

51. Nagano M, Liu M, Inagaki H, Kawada T, Suzuki H. Early intervention with fluoxetine reverses abnormalities in the serotonergic system and behavior of rats exposed prenatally to dexamethasone. Neuropharmacology 2012;63:292-300.

52. Oliveira M, Rodrigues A-J, Leão P, Cardona D, Pêgo JM, Sousa N. The bed nucleus of stria terminalis and the amygdala as targets of antenatal glucocorticoids: implications for fear and anxiety responses. Psychopharmacology (Berl) 2012;220:443-53.

53. Rodrigues AJ, Leão P, Pêgo JM, et al. Mechanisms of initiation and reversal of drugseeking behavior induced by prenatal exposure to glucocorticoids. Mol Psychiatry 2012;17:1295-305.

54. Zuloaga DG, Carbone DL, Handa RJ. Prenatal dexamethasone selectively decreases calretinin expression in the adult female lateral amygdala. Neurosci Lett 2012;521:109_ 14. 


\section{AUTHOR ACCEPTED MANUSCRIPT}

55. Borges S, Coimbra B, Soares-Cunha C, Pêgo JM, Sousa N, Rodrigues AJ.

Dopaminergic Modulation of Affective and Social Deficits Induced by Prenatal

Glucocorticoid Exposure. Neuropsychopharmacology 2013;38:2068-79.

56. Bustamante C, Valencia M, Torres C, et al. Effects of a single course of prenatal betamethasone on dendritic development in dentate gyrus granular neurons and on spatial memory in rat offspring. Neuropediatrics 2014;45:354-61.

57. Iwasa T, Matsuzaki T, Munkhzaya M, et al. Prenatal exposure to glucocorticoids affects body weight, serum leptin levels, and hypothalamic neuropeptide-Y expression in prepubertal female rat offspring. Int J Dev Neurosci Off J Int Soc Dev Neurosci 2014;36:14.

58. Noorlander CW, Tijsseling D, Hessel EVS, et al. Antenatal glucocorticoid treatment affects hippocampal development in mice. PloS One 2014;9:e85671.

59. Pascual R, Valencia M, Larrea S, Bustamante C. Single course of antenatal betamethasone produces delayed changes in morphology and calbindin-D28k expression in a rat's cerebellar Purkinje cells. Acta Neurobiol Exp (Warsz) $2014 ; 74: 415-23$.

60. Virdee K, McArthur S, Brischoux F, et al. Antenatal Glucocorticoid Treatment Induces Adaptations in Adult Midbrain Dopamine Neurons, which Underpin Sexually Dimorphic Behavioral Resilience. Neuropsychopharmacology 2014;39:339-50.

61. Frahm KA, Tobet SA. Development of the blood-brain barrier within the paraventricular nucleus of the hypothalamus: influence of fetal glucocorticoid excess. Brain Struct Funct 2015;220:2225-34. 


\section{AUTHOR ACCEPTED MANUSCRIPT}

62. Lui $\mathrm{C}-\mathrm{C}$, Hsu M-H, Kuo H-C, et al. Effects of melatonin on prenatal dexamethasoneinduced epigenetic alterations in hippocampal morphology and reelin and glutamic acid decarboxylase 67 levels. Dev Neurosci 2015;37:105-14.

63. Pascual R, Valencia M, Bustamante C. Antenatal betamethasone produces protracted changes in anxiety-like behaviors and in the expression of microtubule-associated protein 2, brain-derived neurotrophic factor and the tyrosine kinase $\mathrm{B}$ receptor in the rat cerebellar cortex. Int J Dev Neurosci Off J Int Soc Dev Neurosci 2015;43:78-85.

64. Shende VH, McArthur S, Gillies GE, Opacka-Juffry J. Astroglial Plasticity Is Implicated in Hippocampal Remodelling in Adult Rats Exposed to Antenatal Dexamethasone. Neural Plast 2015;2015:694347.

65. Zeng Y, Brydges NM, Wood ER, Drake AJ, Hall J. Prenatal glucocorticoid exposure in rats: programming effects on stress reactivity and cognition in adult offspring. Stress Amst Neth 2015;18:353-61.

66. Hiroi R, Carbone DL, Zuloaga DG, Bimonte-Nelson HA, Handa RJ. Sex-dependent programming effects of prenatal glucocorticoid treatment on the developing serotonin system and stress-related behaviors in adulthood. Neuroscience 2016;320:43-56.

67. McArthur S, Pienaar IS, Siddiqi SM, Gillies GE. Sex-specific disruption of murine midbrain astrocytic and dopaminergic developmental trajectories following antenatal GC treatment. Brain Struct Funct 2016;221:2459-75.

68. Pascual R, Valencia M, Bustamante $\mathrm{C}$. Effect of antenatal betamethasone administration on rat cerebellar expression of type la metabotropic glutamate receptors (mGluRla) and anxiety-like behavior in the elevated plus maze. Clin Exp Obstet Gynecol 2016;43:5348. 


\section{AUTHOR ACCEPTED MANUSCRIPT}

69. Virdee K, Kentrop J, Jupp B, et al. Counteractive effects of antenatal glucocorticoid treatment on D1 receptor modulation of spatial working memory. Psychopharmacology (Berl) 2016;233:3751-61.

70. Caetano L, Pinheiro $\mathrm{H}$, Patrício $\mathrm{P}$, et al. Adenosine A2A receptor regulation of microglia morphological remodeling-gender bias in physiology and in a model of chronic anxiety. Mol Psychiatry 2017;22:1035-43.

71. Conti M, Spulber S, Raciti M, Ceccatelli S. Depressive-like phenotype induced by prenatal dexamethasone in mice is reversed by desipramine. Neuropharmacology 2017;126:242-9.

72. Tsiarli MA, Rudine A, Kendall N, et al. Antenatal dexamethasone exposure differentially affects distinct cortical neural progenitor cells and triggers long-term changes in murine cerebral architecture and behavior. TransI Psychiatry 2017;7:e1153.

73. Dong W, Xu D, Hu Z, et al. Low-functional programming of the CREB/BDNF/TrkB pathway mediates cognitive impairment in male offspring after prenatal dexamethasone exposure. Toxicol Lett 2018;283:1-12.

74. Frahm KA, Handa RJ, Tobet SA. Embryonic Exposure to Dexamethasone Affects Nonneuronal Cells in the Adult Paraventricular Nucleus of the Hypothalamus. J Endocr Soc $2018 ; 2: 140-53$.

75. Liu W, Wang H, Xue X, et al. OGT-related mitochondrial motility is associated with sex differences and exercise effects in depression induced by prenatal exposure to glucocorticoids. J Affect Disord 2018;226:203-15.

76. Sandman CA, Davis EP, Buss C, Glynn LM. Prenatal programming of human neurological function. Int J Pept 2011;2011:837596. 


\section{AUTHOR ACCEPTED MANUSCRIPT}

77. Brown RW, Diaz R, Robson AC, et al. The ontogeny of 11 beta-hydroxysteroid dehydrogenase type 2 and mineralocorticoid receptor gene expression reveal intricate control of glucocorticoid action in development. Endocrinology 1996;137:794-797.

78. Murphy VE, Clifton VL. Alterations in human placental $11 \beta$-hydroxysteroid dehydrogenase type 1 and 2 with gestational age and labour. Placenta 2003;24:739_ 744.

79. Matthews SG. Antenatal glucocorticoids and programming of the developing CNS. Pediatr Res 2000;47:291-300.

80. Barrada Ml, Blomquist $\mathrm{CH}$, Kotts $\mathrm{C}$. The effects of betamethasone on fetal development in the rabbit. Am J Obstet Gynecol 1980;136:234-8.

81. Frank L, Roberts RJ. Effects of low-dose prenatal corticosteroid administration on the premature rat. Biol Neonate 1979;36:1-9.

82. Moss TJM, Doherty DA, Nitsos I, Sloboda DM, Harding R, Newnham JP. Effects into adulthood of single or repeated antenatal corticosteroids in sheep. Am J Obstet Gynecol 2005;192:146-52.

83. Weinstock M. The long-term behavioural consequences of prenatal stress. Neurosci Biobehav Rev 2008;32:1073-86.

84. Rosen JB, Schulkin J. From normal fear to pathological anxiety. Psychol Rev 1998;105:325-50.

85. Parnaudeau S, Dongelmans M-L, Turiault M, et al. Glucocorticoid receptor gene inactivation in dopamine-innervated areas selectively decreases behavioral responses to amphetamine. Front Behav Neurosci [Internet] 2014 [cited 2019 May 12];8. Available from: https://www.frontiersin.org/articles/10.3389/fnbeh.2014.00035/full 


\section{AUTHOR ACCEPTED MANUSCRIPT}

86. Sidoryk-Wegrzynowicz M, Wegrzynowicz M, Lee E, Bowman AB, Aschner M. Role of astrocytes in brain function and disease. Toxicol Pathol 2011;39:115-23.

87. De Kloet ER, Vreugdenhil E, Oitzl MS, Joëls M. Brain corticosteroid receptor balance in health and disease. Endocr Rev 1998;19:269-301.

88. Jacobson L, Sapolsky R. The role of the hippocampus in feedback regulation of the hypothalamic-pituitary-adrenocortical axis. Endocr Rev 1991;12:118-34.

89. Brownfoot FC, Gagliardi DI, Bain E, Middleton P, Crowther CA. Different corticosteroids and regimens for accelerating fetal lung maturation for women at risk of preterm birth. Cochrane Database Syst Rev [Internet] 2013 [cited 2019 Apr 22];Available from: https://www.cochranelibrary.com/cdsr/doi/10.1002/14651858.CD006764.pub3/abstract

90. Ballard PL, Ballard RA. Scientific basis and therapeutic regimens for use of antenatal glucocorticoids. Am J Obstet Gynecol 1995;173:254-62.

91. Lee BH, Stoll BJ, McDonald SA, Higgins RD, National Institute of Child Health and Human Development Neonatal Research Network. Adverse neonatal outcomes associated with antenatal dexamethasone versus antenatal betamethasone. Pediatrics 2006;117:1503-10.

92. Matthews SG, Challis JRG. Regulation of the hypothalamo-pituitary-adrenocortical axis in fetal sheep. Trends Endocrinol Metab 1996;7:239-46.

93. Matthews SG. Dynamic changes in glucocorticoid and mineralocorticoid receptor mRNA in the developing guinea pig brain. Dev Brain Res 1998;107:123-32.

94. Sapolsky RM, Meaney MJ. Maturation of the adrenocortical stress response: neuroendocrine control mechanisms and the stress hyporesponsive period. Brain Res 1986;396:64-76. 


\section{AUTHOR ACCEPTED MANUSCRIPT}

95. Claman HN. Corticosteroids and Lymphoid Cells. N Engl J Med 1972;287:388-97.

96. Saccone G, Berghella V. Antenatal corticosteroids for maturity of term or near term fetuses: systematic review and meta-analysis of randomized controlled trials. BMJ 2016;355:i5044.

97. Recommendations | Preterm labour and birth | Guidance | NICE [Internet]. [cited 2019 May 19];Available from:

https://www.nice.org.uk/guidance/ng25/chapter/Recommendations\#maternalcorticosteroids

98. Committee on Obstetric Practice. Committee Opinion No. 713: Antenatal Corticosteroid Therapy for Fetal Maturation. Obstet Gynecol 2017;130:e102-9. 


\section{AUTHOR ACCEPTED MANUSCRIPT}

Figure 1. Flow diagram of study selection adapted from PRISMA 2010 (10)

Figure 2. Risk of bias assessment using SYRCLE's risk of bias tool for animal studies (11)

Figure 3. Venn Diagram: break down of studies by reported outcome categories

Figure 4. The regulation of the maternal and fetal HPA axis during pregnancy. The human placenta expresses the genes for proopiomelanocortin and the major stress hormone, corticotropin-releasing hormone $(\mathrm{CRH})$. As pregnancy progresses, these stress hormones including maternal cortisol, increase dramatically. Because of the positive feedback between GCs and placental CRH, the effects of excess endogenous or synthetic GCs may be amplified with potentially negative consequences for the developing fetus. The consequences of prenatal treatment with BM or DM may be more profound as they cross the placenta more easily because they are not readily metabolized by the placental enzyme, $11 \beta$-hydroxysteroid dehydrogenase type 2 (11ß-HSD2), that protects the fetus from maternal cortisol $(77,78)$. These synthetic GCs can gain direct access to glucocorticoid receptors without significant reduction in their circulating or tissue levels due to local oxidation. These endocrine changes are important for fetal maturation, but if the levels are altered (e.g., ACS exposure), they influence (program) the fetal nervous system, especially the meso-cortico-limbic system with long-term consequences. 


\begin{tabular}{|c|c|c|c|c|c|c|c|c|c|c|c|c|}
\hline 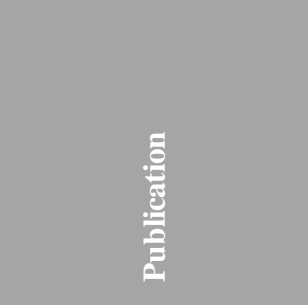 & $\begin{array}{l}\frac{8}{3} \\
\frac{d}{n} \\
\frac{d}{n}\end{array}$ & 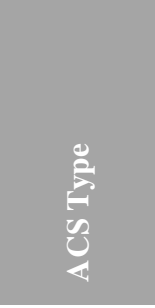 & 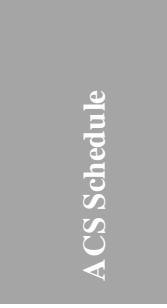 & 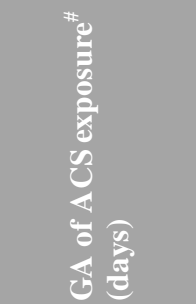 & 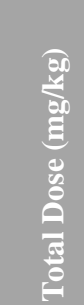 & 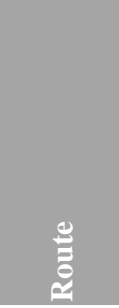 & $\begin{array}{l}\bar{g} \\
0 \\
0 \\
0 \\
0 \\
0 \\
0 \\
0 \\
0\end{array}$ & 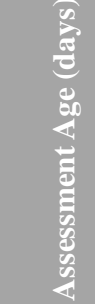 & 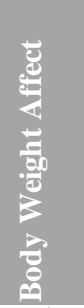 & 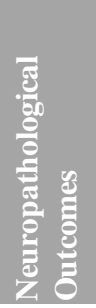 & 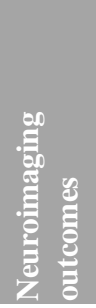 & 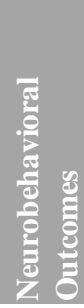 \\
\hline (14) 1975 Smith & Rat & $\mathrm{DM}$ & Multiday & 1-delivery & 0,85 & Mat PO & Yes & 60 & $\rightarrow$ & No & No & Yes \\
\hline (15) 1994 Uno & NHP & $\mathrm{DM}$ & Multiday & $132-133$ & 10,0 & Mat IM & Yes & 270 & - & Yes & Yes & No \\
\hline (16) 1995 Holson & Rat & $\mathrm{DM}$ & Multiday & $14-21$ & 0,80 & Mat SC & No & 90 & $\downarrow$ & No & No & Yes \\
\hline (17) 1997 Muneoka & Rat & $\mathrm{DM}$ & Multiday & $17-19$ & 0,15 & Mat SC & Yes & 98 & $\rightarrow$ & Yes & No & Yes \\
\hline (18) 1997 Rayburn & Mouse & $\mathrm{BM} / \mathrm{DM}$ & Single & 14 & 2,00 & Mat SC & Yes & 135 & - & No & No & Yes \\
\hline (19) 2000 Brabham & Rat & $\mathrm{DM}$ & Multiday & 15-delivery & 1,89 & Mat PO & Yes & 75 & $\downarrow$ & Yes & No & Yes \\
\hline (20) 2001 Christensen & Mouse & $\mathrm{BM}$ & Multiday & $13-16$ & 8,00 & Mat SC & Yes & 120 & - & No & No & Yes \\
\hline (21) 2001 Welberg & Rat & $\mathrm{DM}$ & Multiday & 1-delivery & 0,70 & Mat SC & Yes & 240 & $\downarrow$ & Yes & No & Yes \\
\hline (22) 2002 Dodic & Sheep & $\mathrm{DM}$ & Multiday & $26-28$ & 0,78 & Mat IV & No & 1800 & - & Yes & No & No \\
\hline (23) 2004 Banjanin & Guinea Pig & $\mathrm{DM}$ & Multiday & $\begin{array}{l}40-41,50-51 \\
60-61\end{array}$ & 6,00 & C & es & 150 & $\rightarrow$ & Yes & No & No \\
\hline (24) 2005 Burlet & Rat & DM & Multiday & $15-19$ & 0,50 & Mat SC & Yes & 18 & $\rightarrow$ & No & No & Yes \\
\hline (25) 2005 Hougaard & Rat & DM & Multiday & $14-21$ & 0,80 & Mat SC & Yes & 180 & $\downarrow$ & No & No & Yes \\
\hline (26) 2005 McArthur & Rat & $\mathrm{DM}$ & Multiday & $16-19$ & 0,10 & Mat PO & Yes & 68 & $\rightarrow$ & Yes & No & No \\
\hline (27) 2006 Bruschettini & Rat & $\mathrm{BM}$ & Two doses & 20 & 0,34 & Mat SC & Yes & 21 & $\rightarrow$ & Yes & No & No \\
\hline (28) 2006 Bruschettini & Rat & $\mathrm{BM}$ & Two doses & $20-21$ & 0,34 & Mat SC & Yes & 150 & $\downarrow$ & Yes & No & Yes \\
\hline (29) 2006 Hauser & Rat & $\mathrm{DM}$ & Multiday & $15-21$ & 0,70 & Mat PO & Yes & 135 & $\downarrow$ & No & No & Yes \\
\hline (30) 2006 Korzhevskii & Rat & $\mathrm{DM}$ & Two doses & 13,19 & 2,00 & Mat IV & No & 10 & - & Yes & No & No \\
\hline (31) 2006 Oliveira & Rat & $\mathrm{DM}$ & Two doses & $18-19$ & 2,00 & Mat SC & Yes & 1260 & $\downarrow$ & No & No & Yes \\
\hline (32) 2006 Shoener & Rat & $\mathrm{DM}$ & Multiday & 14-19 & 0,78 & Mat SC & Yes & 21 & $\downarrow$ & Yes & No & No \\
\hline (33) 2006 Velísek & Rat & $\mathrm{BM}$ & Two doses & 15 & 0,80 & Mat IP & Yes & 20 & $\downarrow$ & Yes & No & Yes \\
\hline (34) 2007 Hauser & NHP & DM & Multiday & $42-48,90-96$ & 70,0 & Mat PO & Yes & 84 & $\uparrow$ & No & No & Yes \\
\hline (35) 2007 Leão & Rat & DM & Two doses & $18-19$ & 0,20 & Mat SC & Yes & 21 & - & Yes & No & No \\
\hline (36) 2007 McArthur & Rat & $\mathrm{DM}$ & Multiday & $16-19$ & 0,30 & Mat PO & Yes & 68 & - & Yes & No & No \\
\hline (37) 2007 Owen & Guinea & & Multiday & $\begin{array}{l}40-41,50-51, \\
60-61\end{array}$ & 6,00 & Mat SC & Yes & 10 & - & Yes & No & No \\
\hline (38) 2007 Setiawan & Guinea Pig & $\mathrm{BM}$ & Multiday & $\begin{array}{l}40-41,50-51 \\
60-61\end{array}$ & 5,00 & Mat SC & Yes & 21 & $\rightarrow$ & Yes & No & No \\
\hline (39) 2008 Hauser & NHP & DM & Multiday & $42-48,90-96$ & 35,0 & Mat PO & Yes & 360 & $\rightarrow$ & No & No & Yes \\
\hline (40) 2008 Hossain & Rat & $\mathrm{DM}$ & Multiday & 14-delivery & 0,70 & Mat IP & Yes & 180 & $\rightarrow$ & Yes & No & Yes \\
\hline (41) 2008 Nagano & Rat & $\mathrm{DM}$ & Multiday & $16-21$ & 0,25 & Mat SC & Yes & 70 & $\downarrow$ & Yes & No & Yes \\
\hline (42) 2008 Noorlander & Mouse & DM & Single & 15,5 & 0,40 & Mat IP & Yes & 180 & $\rightarrow$ & Yes & No & Yes \\
\hline (43) 2008 Sloboda & Sheep & $\mathrm{BM}$ & $\begin{array}{l}\text { Single / } \\
\text { multiday }\end{array}$ & $\begin{array}{l}104,111 \\
118,125\end{array}$ & 0,50 & $\begin{array}{l}\text { Mat IM } \\
\text { Fet IM }\end{array}$ & Yes & 123 & - & Yes & No & No \\
\hline (44) 2009 Hauser & Rat & DM & Multiday & 15-delivery & 0,70 & Mat PO & Yes & 300 & $\downarrow$ & No & No & Yes \\
\hline (45) $2010 \mathrm{Diaz}$ & NHP & DM & Multiday & $42-48,90-96$ & 35,0 & Mat PO & Yes & 600 & - & Yes & No & No \\
\hline (46) 2010 Kleinhaus & Rat & $\mathrm{DM}$ & Multiday & $6-8$ & 6,00 & Mat IP & Yes & 29 & $\rightarrow$ & No & No & Yes \\
\hline (47) 2010 Neigh & Rat & $\mathrm{DM}$ & Multiday & $14-21$ & 0,70 & Mat SC & Yes & 90 & - & Yes & No & Yes \\
\hline (48) 2011 Kjaer & Rat & DM & Multiday & $14-21$ & 1,60 & Mat SC & Yes & 210 & - & Yes & No & Yes \\
\hline (49) 2011 Oliveira & Rat & DM & Two doses & $18-19$ & 2,00 & Mat SC & Yes & 90 & - & Yes & No & Yes \\
\hline (50) 2011 Roque & Rat & $\mathrm{DM}$ & Two doses & $18-19$ & 2,00 & Mat SC & Yes & 90 & $\rightarrow$ & No & No & Yes \\
\hline (51) $2012 \mathrm{Li}$ & Sheep & DM & Multiday & $40-42$ & 0,42 & Mat IM & Yes & 210 & - & Yes & No & No \\
\hline (52) $2012 \mathrm{Liu}$ & Rat & $\mathrm{DM}$ & Multiday & $14-21$ & 1,04 & Mat SC & Yes & 63 & $\downarrow$ & No & No & Yes \\
\hline (53) 2012 Nagano & Rat & $\mathrm{DM}$ & Multiday & $16-21$ & 0,30 & Mat SC & Yes & 70 & - & Yes & No & Yes \\
\hline (54) 2012 Oliveira & Rat & $\mathrm{DM}$ & Two doses & $18-19$ & 2,00 & Mat SC & Yes & 90 & - & Yes & No & Yes \\
\hline
\end{tabular}




\section{AUTHOR ACCEPTED MANUSCRIPT}

\begin{tabular}{|c|c|c|c|c|c|c|c|c|c|c|c|c|}
\hline (55) 2012 Rodrigues & Rat & DM & Two doses & $18-19$ & 2,00 & Mat SC & Yes & 120 & - & Yes & No & Yes \\
\hline (56) 2012 Zuloaga & Rat & DM & Multiday & $18-22$ & 2,00 & Mat SC & Yes & 60 & - & Yes & No & No \\
\hline (57) 2013 Borges & Rat & DM & Two doses & $18-19$ & 2,00 & Mat SC & Yes & 98 & - & No & No & Yes \\
\hline (58) 2014 Bustamante & Rat & $\mathrm{BM}$ & Two doses & 20 & 0,34 & Mat SC & Yes & 52 & $\downarrow$ & Yes & No & Yes \\
\hline (59) 2014 Iwasa & Rat & DM & Multiday & 13-delivery & 1,35 & Mat PO & Yes & 28 & $\downarrow$ & Yes & No & No \\
\hline (60) 2014 Noorlander & Mouse & DM & Single & 15.5 & 0,40 & Mat IP & Yes & 180 & $\rightarrow$ & Yes & No & No \\
\hline (61) 2014 Pascual & Rat & $\mathrm{BM}$ & Two doses & 20 & 0,34 & Mat SC & Yes & 52 & - & Yes & No & Yes \\
\hline (62) 2014 Virdee & Rat & DM & Multiday & $16-19$ & 0,20 & Mat PO & Yes & 90 & - & Yes & No & Yes \\
\hline (63) 2015 Frahm & Mouse & DM & Multiday & $11-17$ & 0,70 & Mat SC & Yes & 52 & - & Yes & No & No \\
\hline (64) 2015 Lui & Rat & DM & Multiday & 14-delivery & 0,80 & Mat IP & Yes & 120 & $\rightarrow$ & Yes & Yes & Yes \\
\hline (65) 2015 Pascual & Rat & $\mathrm{BM}$ & Two doses & 20 & 0,34 & Mat SC & Yes & 82 & - & Yes & No & Yes \\
\hline (66) 2015 Shende & Rat & DM & Multiday & $16-19$ & 0,30 & Mat PO & Yes & 68 & - & Yes & Yes & No \\
\hline (67) 2015 Zeng & Rat & DM & Multiday & $15-21$ & 0,70 & Mat SC & Yes & 100 & - & No & No & Yes \\
\hline (68) 2016 Hiroi & Rat & DM & Multiday & $18-22$ & 2,00 & Mat SC & Yes & 60 & - & Yes & No & Yes \\
\hline (69) 2016 McArthur & Mouse & DM & Multiday & $16-19$ & 1,30 & Mat PO & Yes & 67 & - & Yes & No & No \\
\hline (70) 2016 Pascual & Rat & $\mathrm{BM}$ & Two doses & 20 & 0,34 & Mat SC & Yes & 52 & $\rightarrow$ & Yes & No & Yes \\
\hline (71) 2016 Virdee & Rat & DM & Multiday & $16-19$ & 0,30 & Mat PO & Yes & 90 & - & Yes & No & Yes \\
\hline (72) 2017 Caetano & Rat & DM & Two doses & $18-19$ & 2,00 & Mat SC & Yes & 90 & $\rightarrow$ & Yes & No & Yes \\
\hline (73) 2017 Conti & Mouse & DM & Multiday & 14-delivery & 0,25 & Mat SC & Yes & 360 & - & Yes & No & Yes \\
\hline (74) 2017 Tsiarli & Mouse & DM & Single & 14.5 & 0,40 & Mat IP & Yes & 60 & - & Yes & No & Yes \\
\hline (75) 2018 Dong & Rat & DM & Multiday & $9-20$ & 2,40 & Mat SC & No & 182 & $\downarrow$ & Yes & No & Yes \\
\hline (76) 2018 Frahm & Mouse & DM & Multiday & $11-17$ & 0,70 & Mat SC & Yes & 75 & 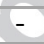 & Yes & No & Yes \\
\hline (77) $2018 \mathrm{Liu}$ & Rat & DM & Multiday & $14-21$ & 1,04 & Mat SC & Yes & 28 & $\downarrow$ & Yes & No & Yes \\
\hline
\end{tabular}

* BM betamethasone, DM dexamethasone, NHP non-human primate, Mat maternal, Fet Fetal, SC subcutaneous, PO per os, IP intraperitoneal, IM intramuscular, IV intravenous

Table 1. Characteristics of included studies. The average gestation period was in mice 19-20

days, rat 22-23 days, guinea pig 65-70days, sheep 145-152 days and non-human primates

144-166 days. Effect indicated as increased $\uparrow$, decreased $\downarrow$ or no significant difference $\rightarrow$.

\begin{tabular}{|c|c|c|c|c|c|c|}
\hline & & $\begin{array}{c}\text { Mouse } \\
n=9\end{array}$ & $\begin{array}{c}\text { Rat } \\
n=45\end{array}$ & $\begin{array}{c}\text { Guinea Pig } \\
n=3\end{array}$ & $\begin{array}{c}\text { Sheep } \\
n=3\end{array}$ & $\begin{array}{l}\text { NHP } \\
n=4\end{array}$ \\
\hline \multirow{3}{*}{$\begin{array}{l}\text { Corticosteroid } \\
\text { Used n (\%) }\end{array}$} & BM & $1(11.1)$ & $7(15.6)$ & $2(66.7)$ & $1(33.3)$ & - \\
\hline & DM & $7(77.8)$ & $38(84.4)$ & $1(33.3)$ & $2(66.7)$ & $4(100)$ \\
\hline & Both & $1(11.1)$ & - & - & - & - \\
\hline \multicolumn{2}{|l|}{ Single course $n(\%)$} & $4(44.4)$ & $16(35.6)$ & - & $1(33.3)$ & - \\
\hline \multicolumn{2}{|c|}{ Total Dose $(\mathrm{mg} / \mathrm{kg})$} & $0,70(0,4-1,3)$ & $0,78(0,34-2,0)$ & $6,00(5,00-6,00)$ & $0,50(0,42-0,78)$ & $35,00(22,5-52,5)$ \\
\hline \multirow{4}{*}{$\begin{array}{l}\text { Total dose (mg/kg) } \\
\text { Number of studies } \\
\text { per steroid type } \\
\text { BM / DM }\end{array}$} & $<0,2$ & - & $-/ 2$ & - & - & - \\
\hline & $0,2-0,4$ & $-/ 4$ & $7 / 7$ & - & - & - \\
\hline & $0,41-1,0$ & $-/ 2$ & $1 / 14$ & - & $2 / 2$ & - \\
\hline & $>1,0$ & $1 / 2$ & $0 / 18$ & $2 / 1$ & - & $-/ 4$ \\
\hline \multirow{5}{*}{ Route n (\%) } & $\mathrm{SC}$ & $5(55.6)$ & $30(66.7)$ & $3(100)$ & - & - \\
\hline & $\mathrm{PO}$ & $1(11.1)$ & $10(22.2)$ & - & - & $3(75)$ \\
\hline & IP & $3(5.9)$ & $4(8.9)$ & - & - & - \\
\hline & $\mathrm{IM}$ & - & - & - & $2(66.7)$ & $1(25)$ \\
\hline & IV & - & $1(2.2)$ & - & $1(33.3)$ & - \\
\hline \multicolumn{2}{|c|}{ Control group used n (\%) } & $9(100)$ & $42(93.3)$ & $3(100)$ & $2(66.7)$ & $4(100)$ \\
\hline \multicolumn{2}{|c|}{ Oldest outcome age (days) } & $120(67-180)$ & $82(52-100)$ & $21(10-150)$ & $210(122-1800)$ & $315(177-480)$ \\
\hline
\end{tabular}

* NHP non-human primate, BM betamethasone, DM dexamethasone, SC subcutaneous, PO per os, IP intraperitoneal, IM intramuscular, IV intravenous. 
Table 2. Details of reported antenatal corticosteroid regimes. Results given as number (n) and percentage (\%) or median with IQR (\#).

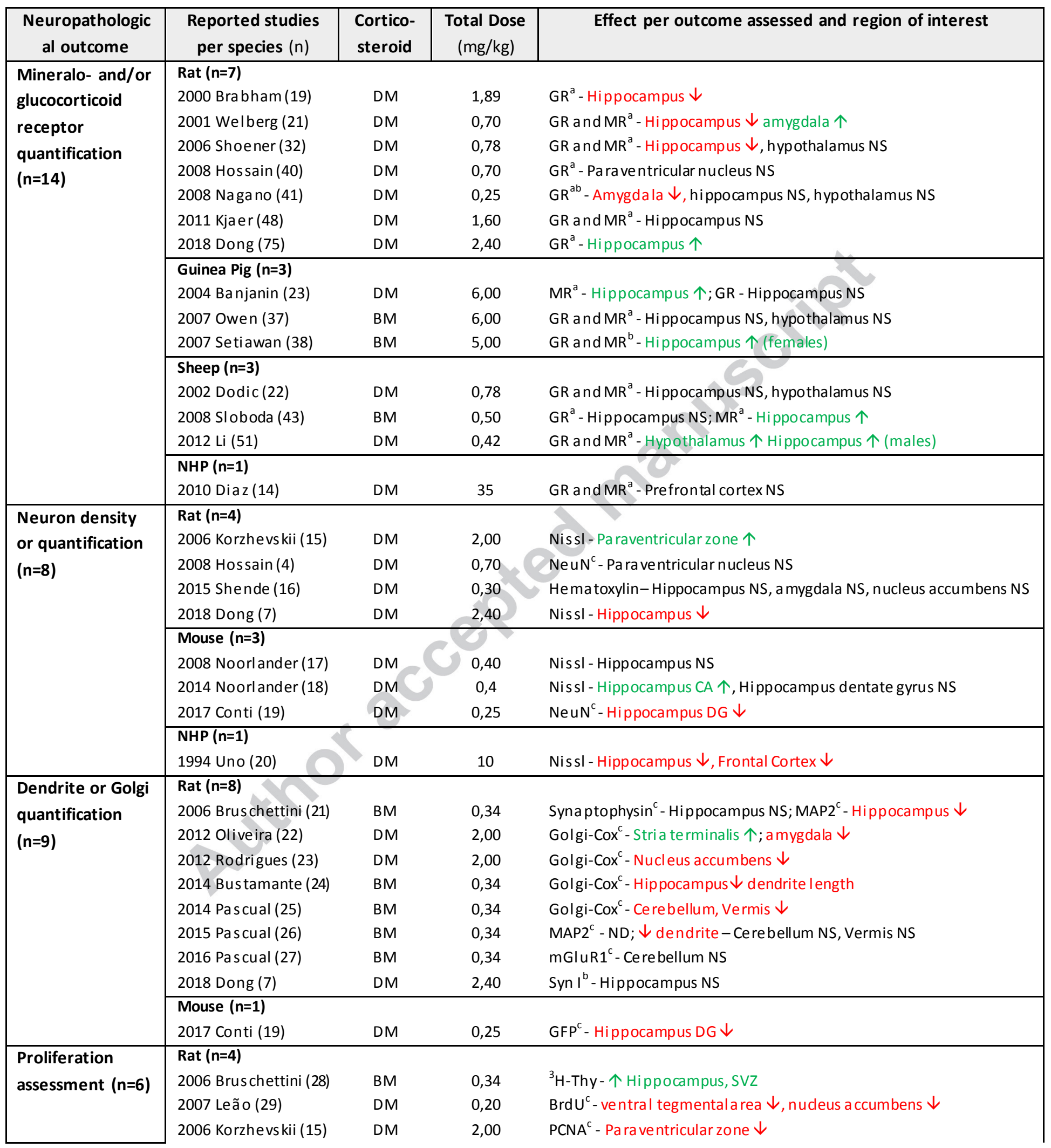


AUTHOR ACCEPTED MANUSCRIPT

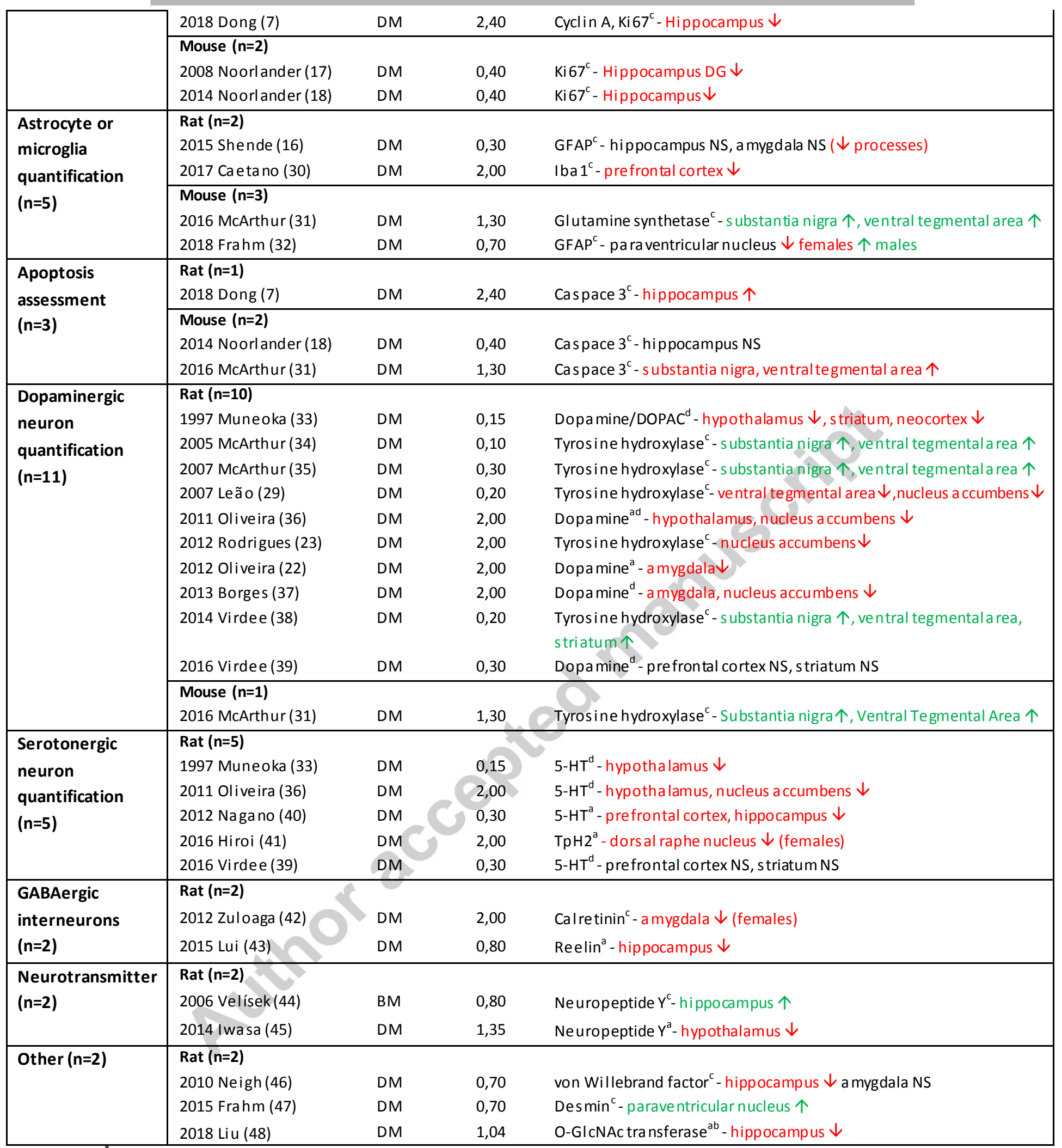

BM betamethasone, DM dexamethasone

${ }^{a}$ Polymerase chain reaction or in situ hybridization, ${ }^{b}$ western blot, ${ }^{c}$ immunocytochemistry, ${ }^{d}$ chromatography 


\section{AUTHOR ACCEPTED MANUSCRIPT}

Table 3. Neuropathological outcome measures reported on in selected studies with specific

staining used. Results given as number $(n)$ with statistically significant effect indicated as

increased $\uparrow$, decreased $\downarrow$ or not significant NS.

\begin{tabular}{|c|c|c|c|c|}
\hline $\begin{array}{l}\text { Reported studies per } \\
\text { species }(n)\end{array}$ & $\begin{array}{l}\text { Neurobehavioral } \\
\text { assessment }(\mathrm{n})\end{array}$ & $\begin{array}{l}\text { Cortico- } \\
\text { steroid }\end{array}$ & $\begin{array}{c}\text { Total } \\
\text { Dose } \\
(\mathrm{mg} / \mathrm{kg})\end{array}$ & Reported significant outcome \\
\hline \multirow[t]{24}{*}{ Open field behavior $(n=22)$} & \multicolumn{4}{|l|}{ Rat $(n=20)$} \\
\hline & 1975 Smith (14) & DM & 0,85 & 个 stress \\
\hline & 1997 Muneoka (17) & DM & 0,15 & $\downarrow$ ambulation, $\downarrow$ rearing \\
\hline & 2001 Welberg (21) & DM & 0,70 & $\downarrow$ ambulation, $\downarrow$ rearing \\
\hline & 2006 Bruschettini (28) & BM & 0,34 & No difference \\
\hline & 2006 Oliveira (31) & DM & 2,00 & $\downarrow$ locomotion, $\downarrow$ explore \\
\hline & 2006 Velísek (33) & BM & 0,80 & $\downarrow$ rearing \\
\hline & 2008 Nagano (41) & DM & 0,25 & $\downarrow$ ambulation, $\downarrow$ rearing \\
\hline & 2009 Hauser (44) & DM & 0,70 & No difference \\
\hline & 2010 Neigh (47) & DM & 0,70 & $\downarrow$ locomotion \\
\hline & 2012 Liu (52) & DM & 1,04 & $\downarrow$ ambulation, $\downarrow$ rearing \\
\hline & 2012 Nagano (53) & DM & 0,30 & $\downarrow$ ambulation, $\downarrow$ rearing \\
\hline & 2012 Rodrigues (55) & DM & 2,00 & $\downarrow$ ambulation \\
\hline & 2014 Pascual (61) & $\mathrm{BM}$ & 0,34 & $\downarrow$ locomotion, $\downarrow$ explore \\
\hline & 2014 Virdee (62) & DM & 0,20 & No difference \\
\hline & 2015 Zeng (67) & DM & 0,70 & No difference \\
\hline & 2016 Hiroi (68) & DM & 2,00 & $\downarrow$ locomotion, $\downarrow$ center time \\
\hline & 2016 Virdee (71) & DM & 0,30 & No difference \\
\hline & 2017 Caetano (72) & DM & 2,00 & No difference \\
\hline & 2018 Dong (75) & DM & 2,40 & No difference \\
\hline & 2018 Liu (77) & DM & 1,04 & $\downarrow$ ambulation, $\downarrow$ rearing \\
\hline & \multicolumn{4}{|l|}{ Mouse $(n=2)$} \\
\hline & 2017 Tsiarli (74) & DM & 0,40 & No difference, $\uparrow$ center time \\
\hline & 2018 Frahm (76) & DM & 0,70 & No difference \\
\hline \multirow[t]{14}{*}{ Elevated plus maze ( $n=13)$} & \multicolumn{4}{|l|}{ Rat $(n=11)$} \\
\hline & 2001 Welberg (21) & DM & 0,70 & $\downarrow$ open arm entries \\
\hline & 2006 Oliveira (31) & DM & 2,00 & $\uparrow$ anxiety \\
\hline & 2006 Velísek (33) & BM & 0,80 & $\uparrow$ latency \\
\hline & 2008 Hossain (40) & DM & 0,70 & $\downarrow$ open arm entries (males) \\
\hline & 2009 Hauser (44) & DM & 0,70 & No difference \\
\hline & 2012 Oliveira (54) & DM & 2,00 & $\downarrow$ open arm entries \\
\hline & 2015 Pascual (65) & BM & 0,34 & $\downarrow$ open arm entries \\
\hline & 2015 Zeng (67) & DM & 0,70 & No difference \\
\hline & 2016 Pascual (70) & $\mathrm{BM}$ & 0,34 & No difference \\
\hline & 2017 Caetano (72) & DM & 2,00 & $\downarrow$ time open arms \\
\hline & 2018 Dong (75) & DM & 2,40 & No difference \\
\hline & \multicolumn{4}{|l|}{ Mouse $(n=2)$} \\
\hline & 1997 Rayburn (18) & $\mathrm{BM}+\mathrm{DM}$ & 2,00 & $\uparrow$ time open arms (BM only) \\
\hline
\end{tabular}




\begin{tabular}{|c|c|c|c|c|}
\hline & 2017 Tsiarli (74) & DM & 0,40 & $\uparrow$ time open arms \\
\hline \multirow[t]{15}{*}{ Forced swim test $(n=13)$} & \multicolumn{4}{|l|}{ Rat $(n=10)$} \\
\hline & 2001 Welberg (21) & DM & 0,70 & 个 Immobile \\
\hline & 2005 Burlet (24) & DM & 0,50 & No difference \\
\hline & 2006 Oliveira (31) & DM & 2,00 & 个 Immobile \\
\hline & 2008 Nagano (41) & DM & 0,25 & No difference \\
\hline & 2009 Hauser (44) & DM & 0,70 & $\uparrow$ female floating time \\
\hline & 2011 Roque (50) & DM & 2,00 & 个 Immobile \\
\hline & 2013 Borges (57) & DM & 2,00 & $\uparrow$ Immobile, $\downarrow$ climbing \\
\hline & 2016 Hiroi (68) & DM & 2,00 & 个 Immobile \\
\hline & 2017 Caetano (72) & DM & 2,00 & No difference \\
\hline & 2018 Liu (77) & DM & 1,04 & 个Immobile \\
\hline & \multicolumn{4}{|l|}{ Mouse $(n=3)$} \\
\hline & 1997 Rayburn (18) & $B M+D M$ & 2,00 & No difference \\
\hline & 2017 Conti (73) & DM & 0,25 & 个 Immobile \\
\hline & 2017 Tsiarli (74) & DM & 0,40 & $\downarrow$ Immobile \\
\hline \multirow[t]{11}{*}{ Morris water maze $(n=9)$} & \multicolumn{4}{|l|}{ Rat $(n=7)$} \\
\hline & 2000 Brabham (19) & DM & 1,89 & $\uparrow$ trial blocks \\
\hline & 2006 Bruschettini (28) & BM & 0,34 & No difference \\
\hline & 2006 Oliveira (31) & DM & 2,00 & No difference \\
\hline & 2009 Hauser (44) & DM & 0,70 & No difference \\
\hline & 2015 Lui (64) & DM & 0,80 & No difference \\
\hline & 2015 Zeng (67) & DM & 0,70 & No difference \\
\hline & 2018 Dong (75) & DM & 2,40 & 个 latency, $\uparrow$ distance \\
\hline & \multicolumn{4}{|l|}{ Mouse $(n=2)$} \\
\hline & \multirow{2}{*}{\multicolumn{4}{|c|}{$\begin{array}{l}2001 \text { Christensen (20) } \\
2008 \text { Noorlander (42) }\end{array}$}} \\
\hline & & DM & 0,40 & 个 latency, $\uparrow$ distance \\
\hline \multirow[t]{9}{*}{ Acoustic startle $(n=7)$} & \multicolumn{4}{|l|}{ Rat $(n=6)$} \\
\hline & 2005 Hougaard (78) & DM & 0,80 & $\uparrow$ response \\
\hline & 2008 Hossain (40) & DM & 0,70 & $\uparrow$ startleamplitude \\
\hline & 2010 Kleinhaus (46) & DM & 6,00 & $\downarrow$ startleamplitude \\
\hline & 2011 Kjaer (48) & DM & 1,60 & 个 startleamplitude \\
\hline & 2012 Oliveira (54) & DM & 2,00 & 个 startleamplitude \\
\hline & 2014 Virdee (62) & DM & 0,20 & No difference \\
\hline & \multicolumn{4}{|l|}{ Mouse $(n=1)$} \\
\hline & 1997 Rayburn (18) & $\mathrm{BM}+\mathrm{DM}$ & 2,00 & $\downarrow$ response(DM only) \\
\hline \multirow[t]{7}{*}{ Prepulse inhibition $(n=6)$} & \multicolumn{4}{|l|}{ Rat $(n=6)$} \\
\hline & 2005 Hougaard (78) & DM & 0,80 & No difference \\
\hline & 2006 Hauser (29) & DM & 0,70 & No difference \\
\hline & 2010 Kleinhaus (46) & DM & 6,00 & $\uparrow$ level, $\uparrow$ efficiency \\
\hline & 2011 Kjaer (48) & DM & 1,60 & No difference \\
\hline & 2012 Oliveira (54) & DM & 2,00 & No difference \\
\hline & 2014 Virdee (62) & DM & 0,20 & $\uparrow$ responsein males \\
\hline \multirow{4}{*}{$\begin{array}{l}\text { Sucrose preference test } \\
(n=5)\end{array}$} & \multicolumn{4}{|l|}{ Rat $(n=5)$} \\
\hline & 2010 Neigh (47) & DM & 0,70 & $\downarrow$ Preference \\
\hline & 2011 Roque (50) & DM & 2,00 & $\downarrow$ Preference \\
\hline & 2012 Liu (52) & DM & 1,04 & $\downarrow$ Preference \\
\hline
\end{tabular}




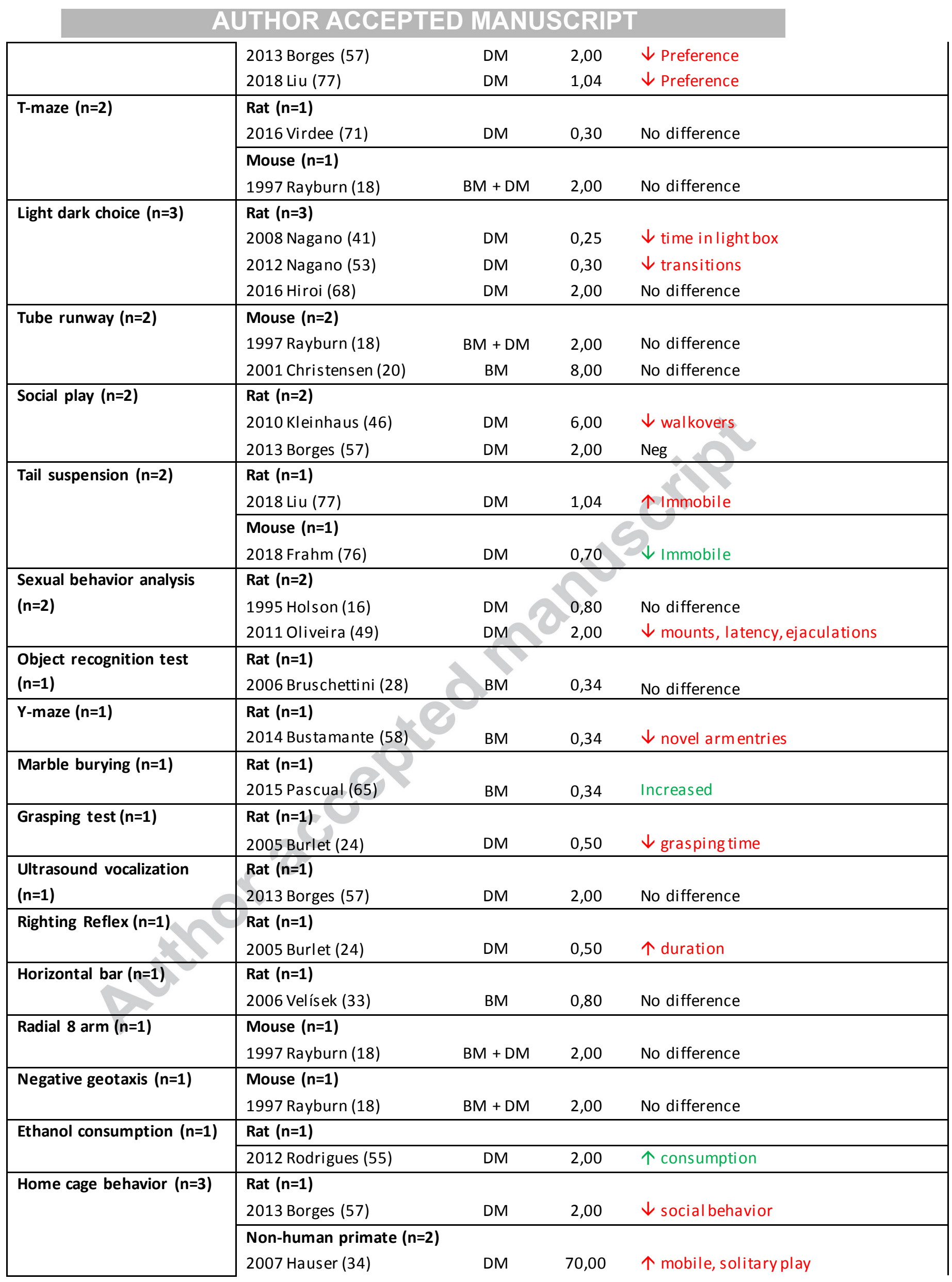




\section{AUTHOR ACCEPTED MANUSCRIPT}

\begin{tabular}{|l|llll|}
\hline & 2008 Hauser (39) & DM & 35,00 & 个 mobile, $\downarrow$ social play, $\downarrow$ exploration \\
\hline $\begin{array}{llll}\text { Cambridge Neuropsychological } \\
\text { Test Automated Battery }(\mathbf{n}=\mathbf{1})\end{array}$ & $\begin{array}{l}\text { Non-human primate }(\mathbf{n}=\mathbf{1}) \\
\text { 2008 Hauser (39) }\end{array}$ & DM & 35,00 & $\uparrow$ responses, $\uparrow$ rewards (females) \\
\hline
\end{tabular}

* BM betamethasone, DM dexamethasone

Table 4. Neurobehavioral assessments reported on in selected studies, per specie and type of antenatal corticosteroid used including the reported significant outcomes. 
Records identified through database searching $(n=575)$
Additional records identified through other sources

$$
(n=94)
$$

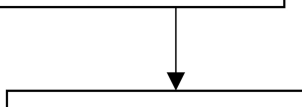

Records excluded $(n=286)$

Records after duplicates (273) and duplicate publications $(0)$ removed
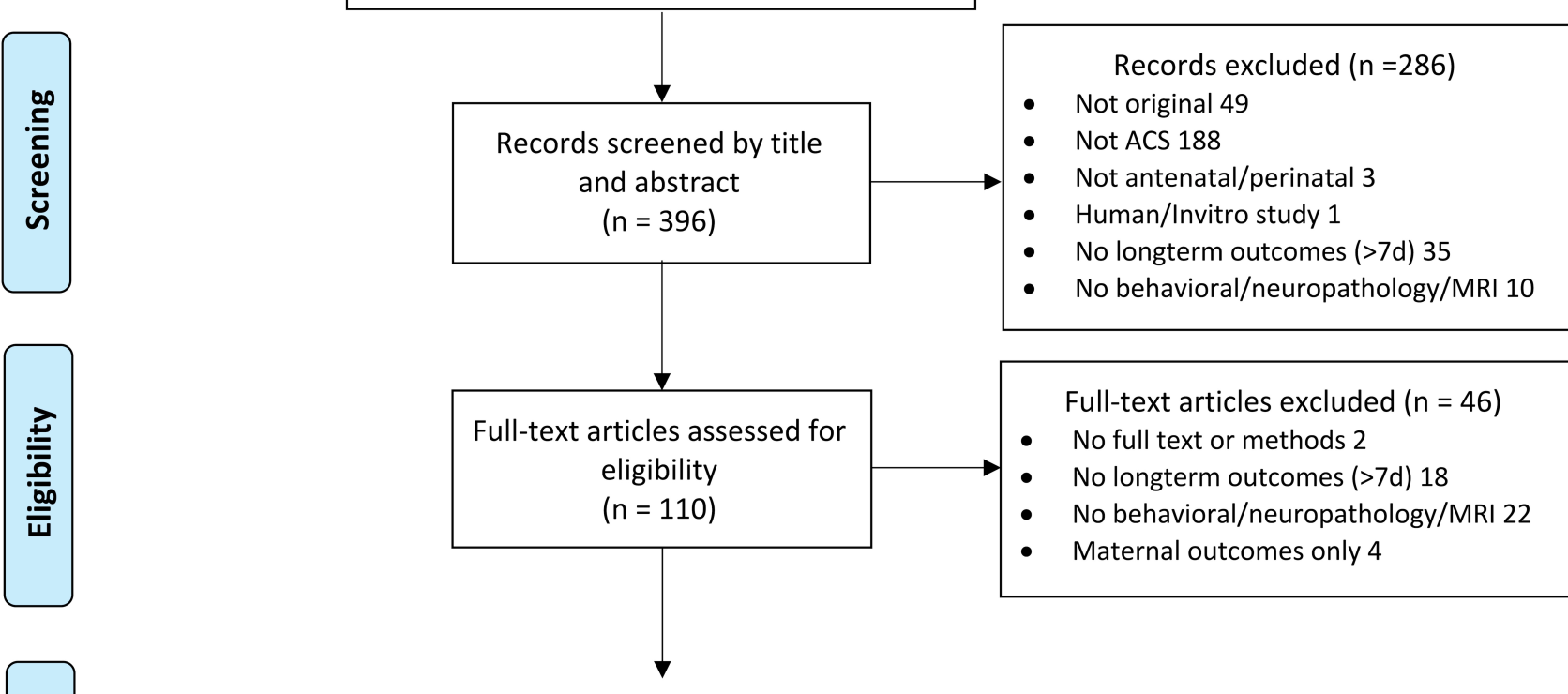

Full-text articles excluded $(n=46)$

- No full text or methods 2

- No longterm outcomes (>7d) 18

- No behavioral/neuropathology/MRI 22

- Maternal outcomes only 4

Studies included in qualitative synthesis

$$
(n=64)
$$




\section{$\begin{array}{llllll}0 \% & 20 \% & 40 \% & 60 \% & 80 \% & 100 \%\end{array}$}

Sequence generation Baseline characteristics Allocation concealment Random housing Blinding (caregivers) Random outcome assessment Blinding (assessor) Incomplete outcome data Selective outcome reporting Other sources of bias

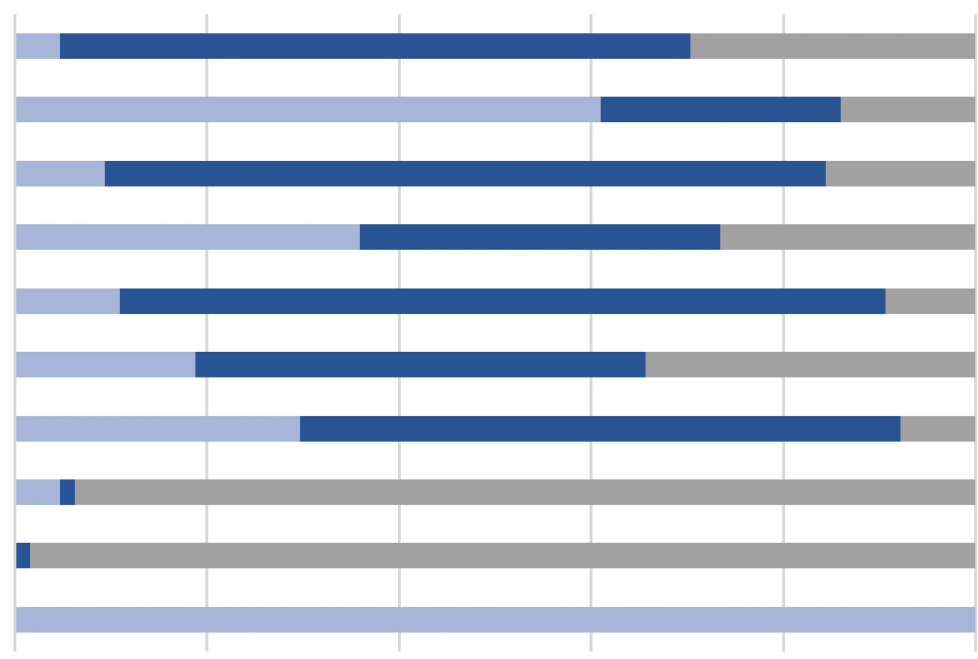

\section{Low High Unclear}

(C) 2019 Macmillan Publishers Limited, part of Springer Nature. 


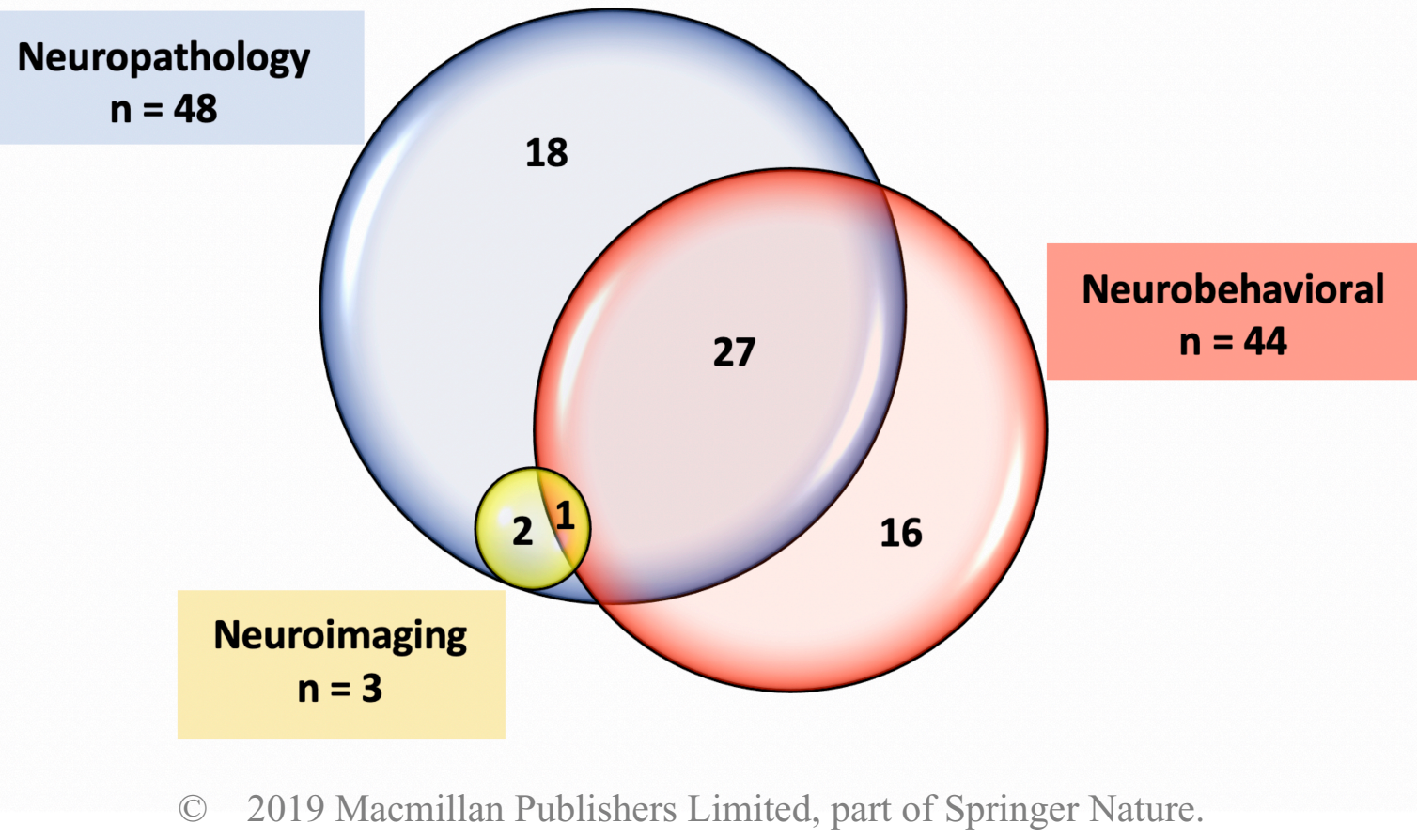




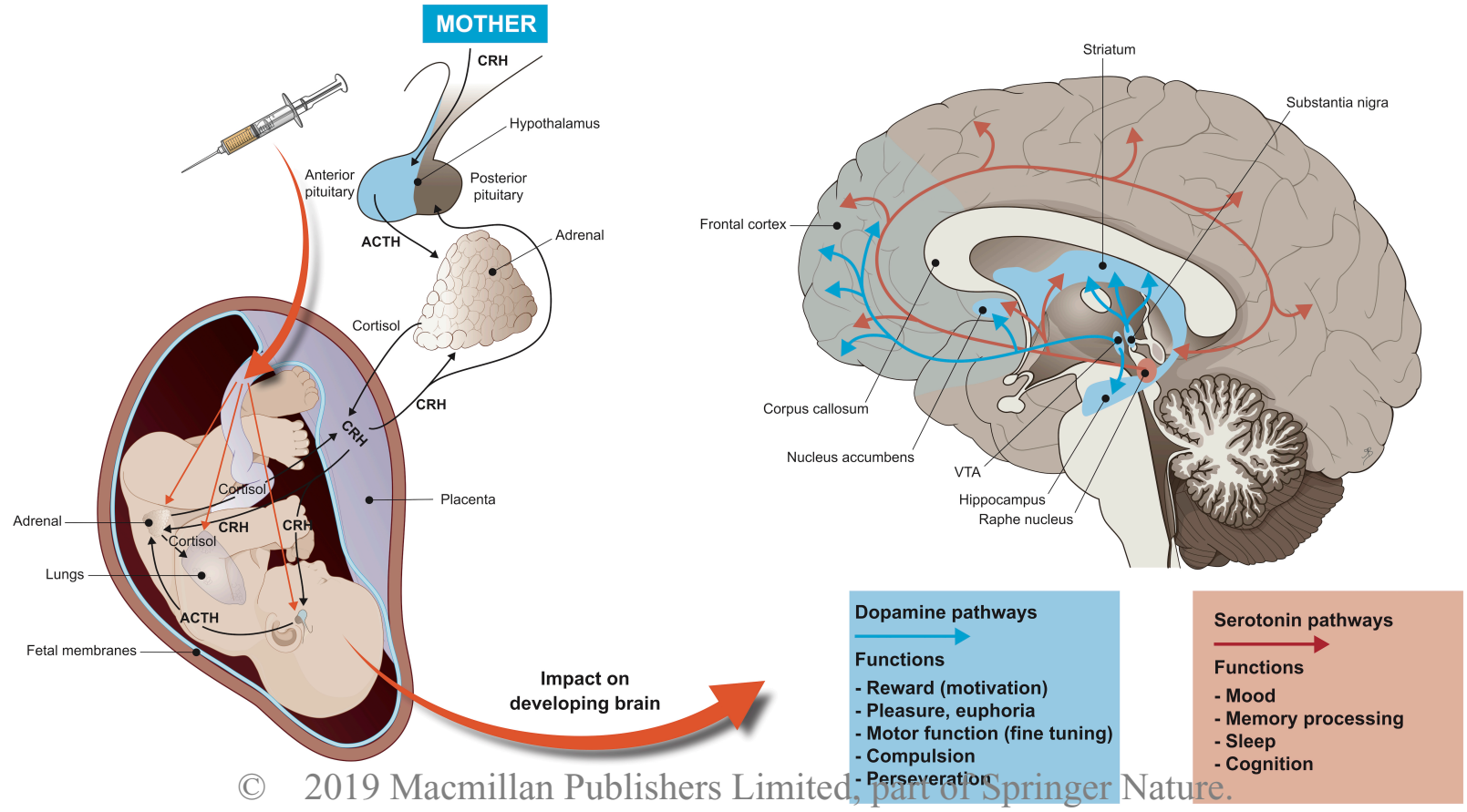

